\title{
Acute Basilar Artery Occlusion: Early Computed Tomography Finding Predicts Catastrophic Outcome
}

Sir,

Basilar artery occlusion (BAO) is not common, but a potentially fatal neurological emergency. The clinical spectrum ranges from mild dizziness to tetraparesis or locked-in syndrome. Computed tomography (CT) of the brain, although insensitive, can be highly valuable in detecting early sign of BAO. We report a case of acute BAO secondary to cardioembolism with hyperdense basilar artery sign on noncontrasted CT brain. The patient was beyond the window period for intravenous thrombolysis and devoid of the availability of endovascular treatment. She was managed medically and expired on the $3^{\text {rd }}$ day of admission. We emphasize the importance of the recognition of hyperdense basilar artery sign on noncontrasted CT scan, as earlier intervention can be initiated to prevent the disastrous outcome.

A 40-year-old female with underlying Type II diabetes mellitus and hypertension presented to the emergency department with a sudden loss of consciousness preceded by vomiting and giddiness. Her blood pressure was $190 / 100 \mathrm{mmHg}$, heart rate was 150 beats/ min, and Glasgow coma scale was E3V1M4 (8/15). Neurological examination revealed right complete ophthalmoplegia and dense left hemiplegia. The initial National Institutes of Health Stroke Scale at $6 \mathrm{~h}$ was 30. Electrocardiography showed fast atrial fibrillation at the rate of 150 beats/min. Urgent noncontrasted $\mathrm{CT}$ of the brain showed hyperdense basilar artery sign [Figure 1a]. Blood investigations for full blood count, serum electrolytes, and blood glucose were within normal range. She rapidly deteriorated in the emergency department and needed to be intubated subsequently. Intravenous thrombolysis was not given in view of her late presentation. She was started on oral aspirin $100 \mathrm{mg}$ daily and admitted to the Intensive Care Unit. Repeated CT brain at $24 \mathrm{~h}$ showed massive infarction at the brainstem and bilateral cerebellum [Figure 1b]. Unfortunately, she succumbed to the illness on the $3^{\text {rd }}$ day of admission despite optimal medical therapy.

Acute $\mathrm{BAO}$ is a potentially lethal condition. It is a subset of posterior circulation stroke, representing $1 \%$ of all ischemic stroke. ${ }^{[1]}$ BAO often poses a diagnostic challenge to clinicians as the symptoms can be fluctuating or mimicking other nonneurological conditions. Dizziness and vertigo, commonly the early symptoms of $\mathrm{BAO}$, need to be cautiously assessed not to miss the possible posterior circulation stroke.

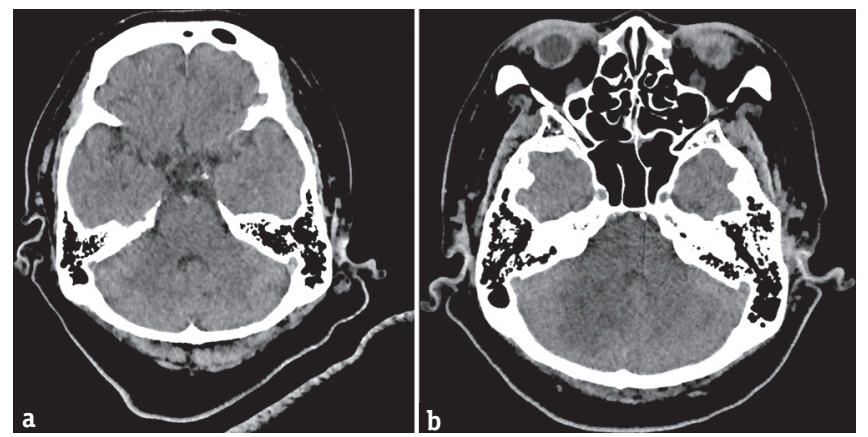

Figure 1: Axial view of noncontrasted computed tomography brain. The basilar artery is hyperdense (a). There are hypodensities seen at brainstem and bilateral cerebellum on repeated computed tomography brain at $24 \mathrm{~h}(\mathrm{~b})$

Magnetic resonance imaging (MRI) with angiography and CT angiography (CTA) of the brain have been shown to be highly sensitive to detect BAO. However, noncontrasted CT brain is usually the first and probably the only available investigation, especially in a center with limited resources. Hyperdense basilar artery sign on noncontrasted CT brain, although insensitive, can be the only sign before a full-blown infarction. It has a strong predictor of acute basilar artery thrombosis in high pretest probability of posterior circulation stroke. ${ }^{[2]}$ Thus, detailed evaluation of the CT film, including comparison of the density of the basilar artery vessel and other intracranial vessels, is required.

The current evidence for acute treatment of BAO remains intravenous thrombolysis with alteplase within $4.5 \mathrm{~h}$ from symptom onset. ${ }^{[3]}$ In recent years, there are studies on endovascular treatment showing good clinical outcomes beyond $4.5 \mathrm{~h}$, even up to $48 \mathrm{~h}$ from symptom onset. ${ }^{[4,5]}$ However, there is no large, randomized clinical trial in comparing medical treatment with endovascular treatment to date in BAO. The best treatment approach still needs to be ascertained in the future.

In conclusion, hyperdense basilar artery sign on noncontrasted CT brain should always be looked up for, as it is highly specific and diagnostic in clinically suspected acute BAO. In a center with the availability of advanced imaging, CTA or MRI with angiography of the brain should be done to confirm the diagnosis, especially for patients who are eligible for endovascular treatment.

\section{Declaration of patient consent}

The authors certify that they have obtained all appropriate patient consent forms. In the form the patient(s) has/have given his/her/their consent for his/ her/their images and other clinical information to be 
reported in the journal. The patients understand that their names and initials will not be published and due efforts will be made to conceal their identity, but anonymity cannot be guaranteed.

\section{Financial support and sponsorship}

Nil.

\section{Conflicts of interest}

There are no conflicts of interest.

Chen Fei Ng, Chia Yin Chong ${ }^{1}$

Department of Medicine, Universiti Kebangsaan Malaysia Medical Centre, Kuala Lumpur, 'Department of Radiology, Ampang Hospital, Selangor Malaysia

Address for correspondence: Dr. Chen Fei Ng, Department of Medicine, Universiti Kebangsaan Malaysia Medical Centre, Jalan Yaacob Latif, Bandar Tun Razak, 56000 Cheras, Kuala Lumpur, Malaysia. E-mail: n.chenfei@gmail.com

\section{REFERENCES}

1. Mattle HP, Arnold M, Lindsberg PJ, Schonewille WJ, Schroth G. Basilar artery occlusion. Lancet Neurol 2011;10:1002-14.

2. Goldmakher GV, Camargo EC, Furie KL, Singhal AB, Roccatagliata L, Halpern EF, et al. Hyperdense basilar artery sign on unenhanced CT predicts thrombus and outcome in acute posterior circulation stroke. Stroke 2009;40:134-9.
3. Hacke W, Kaste M, Bluhmki E, Brozman M, Dávalos A, Guidetti D, et al. Thrombolysis with alteplase 3 to 4.5 hours after acute ischemic stroke. N Engl J Med 2008;359:1317-29.

4. Demel SL, Broderick JP. Basilar occlusion syndromes: An update. Neurohospitalist 2015;5:142-50.

5. Berkhemer OA, Fransen PS, Beumer D, van den Berg LA, Lingsma HF, Yoo AJ, et al. A randomized trial of intraarterial treatment for acute ischemic stroke. $N$ Engl $J$ Med $2015 ; 372: 11-20$

This is an open access journal, and articles are distributed under the terms of the Creative Commons Attribution-NonCommercial-ShareAlike 4.0 License, which allows others to remix, tweak, and build upon the work non-commercially, as long as appropriate credit is given and the new creations are licensed under the identical terms.

\begin{tabular}{|l|l|}
\hline \multicolumn{2}{|c|}{ Access this article online } \\
\hline Quick Response Code: & Website: \\
\hline & \\
\cline { 2 - 2 } & \\
\hline
\end{tabular}

How to cite this article: $\mathrm{Ng} \mathrm{CF}$, Chong CY. Acute basilar artery occlusion: Early computed tomography finding predicts catastrophic outcome. J Neurosci Rural Pract 2018;9:653-4.

(c) 2018 Journal of Neurosciences in Rural Practice | Published by Wolters Kluwer - Medknow 